\title{
Why do miRNAs live in the miRNP?
}

\author{
Dianne S. Schwarz and Phillip D. Zamore ${ }^{1}$ \\ Department of Biochemistry and Molecular Pharmacology, University of Massachusetts Medical School, \\ Worcester, Massachusetts 01605, USA
}

\section{Do tiny RNAs now have a home?}

Noncoding RNAs function in diverse pathways-dosage compensation, gene imprinting, transcriptional regulation, pre-mRNA splicing, and the control of mRNA translation-and they carry out these roles from within specific RNA-protein complexes that ensure each noncoding RNA is in the right cellular compartment with the appropriate proteins needed to accomplish its biochemical function. Thus, identifying the ribonucleoprotein complex (RNP) associated with a noncoding RNA gives clues to its cellular function and biochemical mechanism by revealing the proteins whose company it keeps. The discovery by Dreyfuss and coworkers that microRNAs reside in a $\sim 550-\mathrm{kD}$ (15S) particle provides new clues toward the functions of this novel and surprisingly large class of tiny, noncoding RNAs (Mourelatos et al. 2002).

The first microRNA, (miRNA) lin-4, was identified in 1993 (Lee et al. 1993). Ambros and coworkers positionally cloned the lin-4 gene, a locus required for the correct timing of development in Caenorhabditis elegans, only to find that the gene encodes no protein (Lee et al. 1993). Instead, lin-4 comprises two small noncoding RNAs, one 22 nucleotides long, and a longer form, lin- $4 L$, that can fold into a hairpin structure. Seven years later, Ruvkun and colleagues discovered that let-7, which likewise regulates developmental timing in worms, is also a tiny, noncoding RNA (Reinhart et al. 2000). Because lin-4 and let-7 control developmental timing, they have been dubbed small temporal RNAs (stRNAs). Recently, three laboratories succeeded in cloning additional stRNA-like RNAs from worms, flies, and human cells (Lagos-Quintana et al. 2001; Lau et al. 2001; Lee and Ambros 2001). These efforts uncovered a wealth of 19-25 nucleotide RNAs, including lin-4 and let-7, which are collectively known as miRNAs (for reviews, see Moss 2001; Ruvkun 2001; Banerjee and Slack 2002). These efforts added an additional 100 tiny RNAs to the original pair of stRNAs. As anticipated by Ambros, stRNAs and miRNAs derive from longer stem-loop precursor RNAs. Thus, the longer lin- $4 L$ is the precursor of mature lin-4. Whereas many of

${ }^{1}$ Corresponding author.

E-MAIL phillip.zamore@umassmed.edu; FAX (508) 856-2003.

Article and publication are at http://www.genesdev.org/cgi/doi/10.1101/ gad.992502. the new miRNAs are produced constitutively, some are temporally regulated or expressed only in specific tissues. A few appear to be transcribed in coordinately regulated operons, suggesting that they are cleaved from their stem-loop precursors from within a long, common transcript. Others are found only in the germ line or in the early embryo, in which translational control dominates the hierarchy of regulatory mechanisms.

The 21-25 nucleotide size of miRNAs is remarkably similar to that of small interfering RNAs (siRNAs), the 21-25 nucleotide double-stranded RNAs that mediate RNA interference (for reviews, see Bernstein et al. 2001b; Carthew 2001; Sharp 2001; Vaucheret et al. 2001; Waterhouse et al. 2001). siRNAs are generated by the endonucleolytic cleavage of long double-stranded RNA by the multidomain RNase III enzyme, Dicer (Bernstein et al. 2001a). siRNAs are then incorporated into a $\sim 500-\mathrm{kD}$ RNP complex, the RNA-induced silencing complex (RISC), in which they provide the specificity determinants that direct an as yet unidentified protein nuclease to cleave mRNAs complementary to the siRNA (Hammond et al. 2000). lin-4 and let-7, as well as the new miRNAs, are encoded by $\sim 70$ nucleotide stem-loop structures (Lee et al. 1993; Pasquinelli et al. 2000), whose stems are substrates for processing by Dicer (Grishok et al. 2001; Hutvágner et al. 2001; Ketting et al. 2001). Dicer liberates miRNAs from the larger stem-loop precursors in much the same way it generates siRNAs from long dsRNA, leaving the signature 3' hydroxyl and 5' phosphate termini of an RNase III cleavage reaction. Both siRNA and stRNA production by Dicer requires ATP, consistent with the presence of an ATP-dependent helicase domain at the amino terminus of Dicer (Zamore et al. 2000; Bernstein et al. 2001a; Hutvágner et al. 2001; Nykänen et al. 2001). Mature lin-4 and let-7 are thought to bind partially complementary sequences in the 3 ' UTRs of their target mRNAs (Lee et al. 1993; Reinhart et al. 2000). Unlike the binding of siRNAs, which triggers target RNA destruction, binding of the stRNA lin-4, and likely let-7, leads to translational repression of their natural mRNA targets (Olsen and Ambros 1999; Reinhart et al. 2000; Slack et al. 2000). In worms, translational repression of lin-4 and let-7 target mRNAs is required for the progression from one stage of development to the next.

In addition to Dicer, two members of the PPD family of proteins, ALG-1 and ALG-2, are required for the bio- 
genesis or function of lin-4 and let-7 in worms (Grishok et al. 2001). PPD proteins, so named because they contain PAZ and Piwi domains, protein sequence motifs of unknown biochemical function, are required for a diverse array of developmental functions in plants and animals. alg-1/alg-2 mutants accumulate 1 in- 4 and let-7 precursors and display striking defects in developmental timing (Grishok et al. 2001). Worms lacking alg-2 also fail to form a normal germ line (Cikaluk et al. 1999). A role for PPD proteins in the biogenesis or function of miRNAs has only been shown for the PPD proteins ALG-1 and ALG-2 in worms, but it seems likely that PPD proteins will be needed for miRNA biogenesis in other organisms.

PPD proteins function not only in miRNA maturation, but are also required in animals, plants, and fungi for a variety of RNA-silencing phenomena, including RNAi and cosuppression, the RNAi-like silencing of an endogenous gene by a transgene copy of the same sequence (Tabara et al. 1999; Catalanotto et al. 2000; Fagard et al. 2000; Hammond et al. 2001; Pal-Bhadra et al. 2002). In C. elegans, the PPD protein RDE-1 is required for RNAi (but not cosuppression; Tabara et al. 1999, Dernburg et al. 2000; Ketting and Plasterk 2000); QDE-2 is required for cosuppression in the fungus Neurospora crassa (Catalanotto et al. 2000); and Argonaute is required both for RNA silencing and for normal meristem function in plants (Bohmert et al. 1998; Fagard et al. 2000). In flies, the PPD protein, Piwi, is required for the maintenance of germ-line stem cells, for the post-transcriptional silencing of endogenous genes by transgenes encoding the same mRNA, and even for some aspects of transcriptional silencing (Cox et al. 1998; Pal-Bhadra et al. 2002). Intriguingly, Piwi localizes to the nucleoplasm, not the cytoplasm, in Drosophila ovaries and testes, but disperses to the cytoplasm during mitosis (Cox et al. 2000). The role of Piwi in post-transcriptional silencing - a phenomenon that all current evidence suggests occurs in the cytoplasm-implies that at least a subpopulation of Piwi functions outside of the nucleus. Might Piwi associate with miRNAs in the cytoplasm, then move as a Piwi-containing miRNP to the nucleus to regulate transcription or nuclear mRNA stability?

The human homolog of Piwi, Hiwi, plays a role in maintaining hematopoetic stem cells, and the mouse homolog, Miwi, is expressed in primordial germ cells, suggesting its function in mammals may parallel that of Piwi in flies (Kuramochi-Miyagawa et al. 2001; Sharma et al. 2001). Another Drosophila PPD protein, Aubergine, is required for the RNAi-like silencing of the Stellate locus in testes, for antero-posterior patterning in the developing embryo, in which it is required for the translation of the developmental regulator Oskar, and for the formation of pole cells, the progenitors of both male and female germ cells (Wilson et al. 1996; Aravin et al. 2001; Harris and Macdonald 2001). Perhaps all of the phenotypes observed for PPD protein mutants arise from their failure to produce specific sets of miRNAs required for germ-line development, stem-cell maintenance, or patterning. Reinforcing this view, worms mutant for Dicer $(d c r-1)$, like those lacking ALG-2, show germ-line defects
(Knight and Bass 2001). Dreyfus and coworkers now find that many human miRNAs are present in a $\sim 550-\mathrm{kD}$ complex, the miRNP, and that this complex contains the PPD protein eIF2C2 (Mourelatos et al. 2002).

Current evidence supports the view that in metazoans, both the RNAi and miRNA pathways require the activity of Dicer and PPD proteins. The RNAi and miRNA pathways are clearly related, but there are features that differentiate them. First, siRNAs are processed from perfectly complementary, long dsRNA into double-stranded siRNAs that guide the destruction of a target mRNA (Hamilton and Baulcombe 1999; Hammond et al. 2000; Zamore et al. 2000; Bernstein et al. 2001a; Elbashir et al. 2001a,b; Nykänen et al. 2001). In contrast, miRNAs are single stranded, processed from $\sim 70$ nucleotide precursors that have the ability to form stem-loop structures containing loops and bulges of unpaired nucleotides. Only one strand of the stem of the miRNA precursor accumulates, indicating that the other strand must either not be produced or is differentially degraded. The fact that multiple PPD proteins are found in various organisms that exhibit RNAi may be an indication that different classes of these proteins play a specialized role in the two pathways. But reality must be more complex than this simple model, which predicts that two PPD proteins-one for RNAi and one for miRNAs-would suffice. Instead, the number of PPD proteins is large and varies greatly in different organisms (Fig. 1): flies have five, humans have four, and Arabidopsis have six, but worms have at least 24 !

\section{Why so many PPD proteins?}

One explanation is that not all PPD proteins function in the RNAi or miRNA pathways. This seems unlikely, as three of the five Drosophila family members have already been implicated in one or another RNA-silencing phenomenon. Perhaps different subclasses of miRNAs require distinct PPD proteins for their production, stability, or function. Such a requirement might reflect the individual peculiarities of a miRNA's sequence or precursor structure, or perhaps the subcellular localization of its target mRNAs. Consistent with this notion, human eIF2C1 (also known as GERp95) is associated with the golgi and ER, in which it might play a specialized role in mediating miRNA-based translational regulation of secreted proteins (Cikaluk et al. 1999; Tahbaz et al. 2001). Alternatively, all PPD proteins might be biochemically interchangeable, but be distinguished by distinct patterns of developmental or tissue-specific expression. For example, in worms, a subset of PPD proteins are more abundant in the germ line than the soma (Reinke et al. 2000). The finding that PPD proteins play important roles in stem-cell production, gametogenesis and patterning may be an indication that different classes of tissue-specific miRNAs regulate gene expression in these key developmental events.

In addition to the PPD protein eIF2C2, the recently discovered miRNP contains at least two more proteins, Gemin3 and Gemin4 (Mourelatos et al. 2002). These pro- 


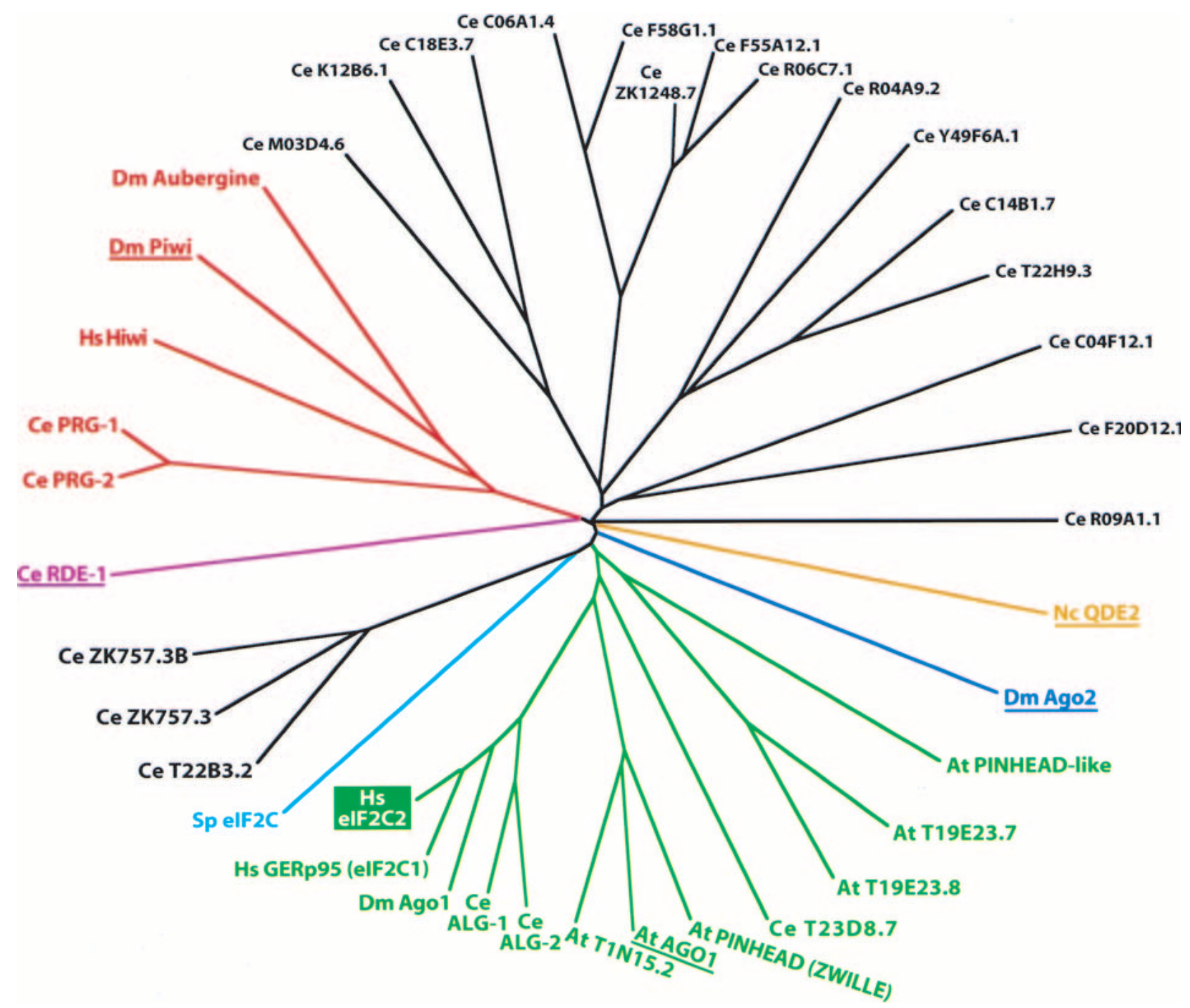

Figure 1. Sequence relationship among PPD proteins. (At) Arabidopsis thaliana; (Ce) Caenorhabditis elegans; (Dm) Drosophila melanogaster; (Nc) Neurospora crassa; (Hs) Homo sapien; (Sp) Schizosaccharomyces pombe. (Red) PIWI subfamily; (green) AGO1 subfamily. Protein alignments were performed using ClustalX and illustrated by TreeView.

teins may interact directly with eIF2C2, because in vitro-translated Gemin3 and Gemin4 bind an eIF2C2glutathione-S-transferase fusion protein (and vice versa). These interactions may be direct or they may be bridged by proteins present in the reticulocyte lysate used for translation. Gemin3 and Gemin4 were identified previously as part of a multi-protein complex containing the Survival of Motor Neurons (SMN) protein, Gemin2 (Charroux et al. 1999, 2000; Mourelatos et al. 2001), Gemin5 (Meister et al. 2001; Gubitz 2002), and Gemin6 (Pelizzoni et al. 2002). The SMN-containing complex is distinct from the miRNP. The SMN complex-comprising SMN, Gemin2, Gemin3, Gemin4, Gemin5, and Gemin6-is found in the nucleus in discrete foci known as gems. The SMN complex functions in the assembly and restructuring of diverse RNP particles, including spliceosomal snRNPs. SMN protein is defective in the neurodegenerative disease, spinal muscular atrophy (SMA). It is, therefore, presumed that the underlying cause of SMA is a failure in snRNP biogenesis or recycling. The sequences of the proteins in the SMN complex has thus far failed to reveal their biochemical function, with the exception of Gemin3, a 105-kD member of the DEAD-box family of putative ATP-dependent RNA helicases.

Gemin3 may provide a catalytic function in the assembly of RNPs (Charroux et al. 1999). Previously, Gemin3 was detected together with Gemin4 in a second complex of $\sim 550 \mathrm{kD}$ (Charroux et al. 1999). In their present work, Dreyfuss and coworkers characterized this second, less abundant complex through a series of coimmunoprecipitations, identifying it as the miRNP (Mourelatos et al. 2002). Two anti-Gemin3-specific monoclonal antibodies were used to characterize Gemin3-containing complexes in total lysates prepared by sonicating human HeLa cells. One antibody recognizes Gemin3 in the SMN complex, whereas the second de- 
tects only Gemin3 protein that is not associated with SMN (Mourelatos et al. 2002). It is this second antibody that immunoprecipates the miRNP. In addition to Gemin3 and Gemin4, this antibody coimmunoprecipitates two proteins with apparent molecular masses of 115 and $95 \mathrm{kD}$, neither of which is found in the SMN complex. Mass spectrometry revealed the $95-\mathrm{kD}$ protein to be the PPD protein eIF2C2, making the first tentative link between the $\sim 550-\mathrm{kD}$ complex and the miRNA and RNAi pathways. Because the SMN complex contains noncoding RNAs (e.g., snRNA), the $\sim 550-\mathrm{kD}$ complex was scrutinized for associated noncoding RNA. Remarkably, miRNAs were found to be tightly associated with the non-SMN, Gemin3-containing complex. In fact, this miRNP appears to be home to at least 40 different miRNAs, all but nine of them not identified in the original screen to clone and sequence human miRNAs (Lagos-Quintana et al. 2001). Like the original tiny RNAs, lin-4 and let-7, each of the new miRNAs is encoded in genomic sequence that can fold to form a $~ 70$-nucleotide precursor RNA.

In addition to colocalizing with the SMN protein in nuclear gems, Gemin3 exhibits a diffuse cytoplasmicstaining pattern that may correspond to the miRNPs. In the recent Dreyfuss study total cell lysates were employed, so the intracellular localization of miRNPs could not be inferred (Mourelatos et al. 2002), but Dicer is a cytoplasmic protein in human cells (Billy et al. 2001), suggesting that miRNA precursors are processed in the cytoplasm by Dicer, which then passes the singlestranded miRNAs to the miRNP. In extracts from cultured Drosophila cells, the PPD protein Ago-2 binds Dicer, directly or indirectly, suggesting that the transfer of mature miRNA from Dicer to the miRNP might be mediated by PPD proteins (Hammond et al. 2001). Dicer does not appear to be a stable component of the miRNP, as no appropriately sized protein $(250 \mathrm{kD})$ coimmunoprecipitates with either anti-eIF2C2 or Gemin3 antibodies, although as an enzyme, Dicer might be present in the miRNP in substoichiometric amounts (Mourelatos et al. 2002). In fact, antibodies to both Gemin3 and eIF2C2 immunoprecipitate 76 -nucleotide-long RNA in addition to the miRNAs, suggesting that miRNA precursors might be present in the miRNP. Might the miRNPs therefore be miRNA birthing centers (Fig. 2)? Like siRNAs, miRNAs are generated by cleavage of a structured RNA precursor by the double-stranded RNAspecific endonuclease Dicer. However, siRNAs are double stranded, whereas miRNAs are single stranded. Are miRNAs single stranded because Dicer cleaves miRNA precursors only at the $5^{\prime}$ and $3^{\prime}$ ends of the mature miRNA sequence? Or, are miRNAs initially double stranded like siRNAs, but then the anti-sense miRNA strand is rapidly destroyed? In this second model, the miRNP might play a role in the dissociation of the two strands, perhaps catalyzed by the putative ATP-dependent helicase Gemin3, with the PPD protein eIF2C2 acting to stabilize the mature miRNA against degradation. The miRNP might even promote degradation of the nonmiRNA strand and the rest of the precursor.

\section{What do miRNAs do?}

A total of 135 distinct miRNAs have been identified thus far in worms, flies, or humans, yet the regulatory function and mRNA targets are known for only C. elegans lin-4 and let-7. The presence of a putative ATP-dependent RNA helicase suggests that the miRNP might catalyze miRNA target recognition. In this regard, it is important to note that target recognition by siRNAs requires no ATP (Nykänen et al. 2001). siRNA-mRNA interactions encompass 21 perfectly complementary base pairs, whereas lin-4 and let-7 form only 14 to 17 Watson-Crick base pairs with their target mRNAs. Therefore, the weaker stRNA-mRNA and putative miRNA-mRNA interactions may require the aid of an ATP-dependent helicase to remove local secondary structure in the target mRNA or perhaps even to zipper the miRNA to its target sequence. Finally, a helicase might, in principle, act to recycle miRNAs, although if miRNAs function as translational regulators, they would likely form a stoichiometric complex with their regulatory targets and turnover infrequently. If, like lin-4 and let-7, miRNAs are sequence-specific translational repressors that bind their targets through $3^{\prime}$ UTR sequences, the miRNP might correspond to the actual mediator of translational repression. In support of this idea, a significant fraction of human eIF2C2, Gemin3, and Gemin 4 cosediment in a sucrose gradient with the ribosomal pellet (Mourelatos et al. 2002), as has been reported also for the RNAi-associated PPD protein Ago-2 from extracts of cultured fly cells (Hammond et al. 2001). It has not yet been determined whether this cosedimentation reflects an actual association of either eIF2C2 or Ago-2 with ribosomes, although the miRNA lin-4 has been shown to be directly associated with polysomal lin14 mRNA, whose translation it represses/Olsen and Ambros 1999). Furthermore, eIF2C2 is $85 \%$ identical to eIF2C1, which was originally identified as a translational initiation cofactor (Zou et al. 1998; Koesters et al. 1999). It is important to note that although purified fractions containing the eIF2C1 protein were shown to enhance translational initiation in vitro, no biochemical activity has yet been shown for the protein that was cloned as eIF2C1, and that mRNA repression by lin-4 occurs at a step after translational initiation. It is also important to recall that outside of $C$. elegans, no function has been ascribed to any miRNA, including Drosophila and human let-7. Thus, miRNAs may act not only as translational regulators, but also to modulate mRNA stability or to direct mRNA localization. It is conceivable that some may even provide sequence specificity to regulators of transcription.

Of the 135 miRNAs identified thus far, none is perfectly complementary to any known mRNA in the worm, fly, or human genome. It is therefore unlikely that miRNAs act in the destruction of mRNA in vivo, because effective RNAi requires a high degree of complementarity between the siRNA and the target RNA (Elbashir et al. 2001b). As the RNAi pathway is thought to defend eukaryotic cells against colonization by parasitic 


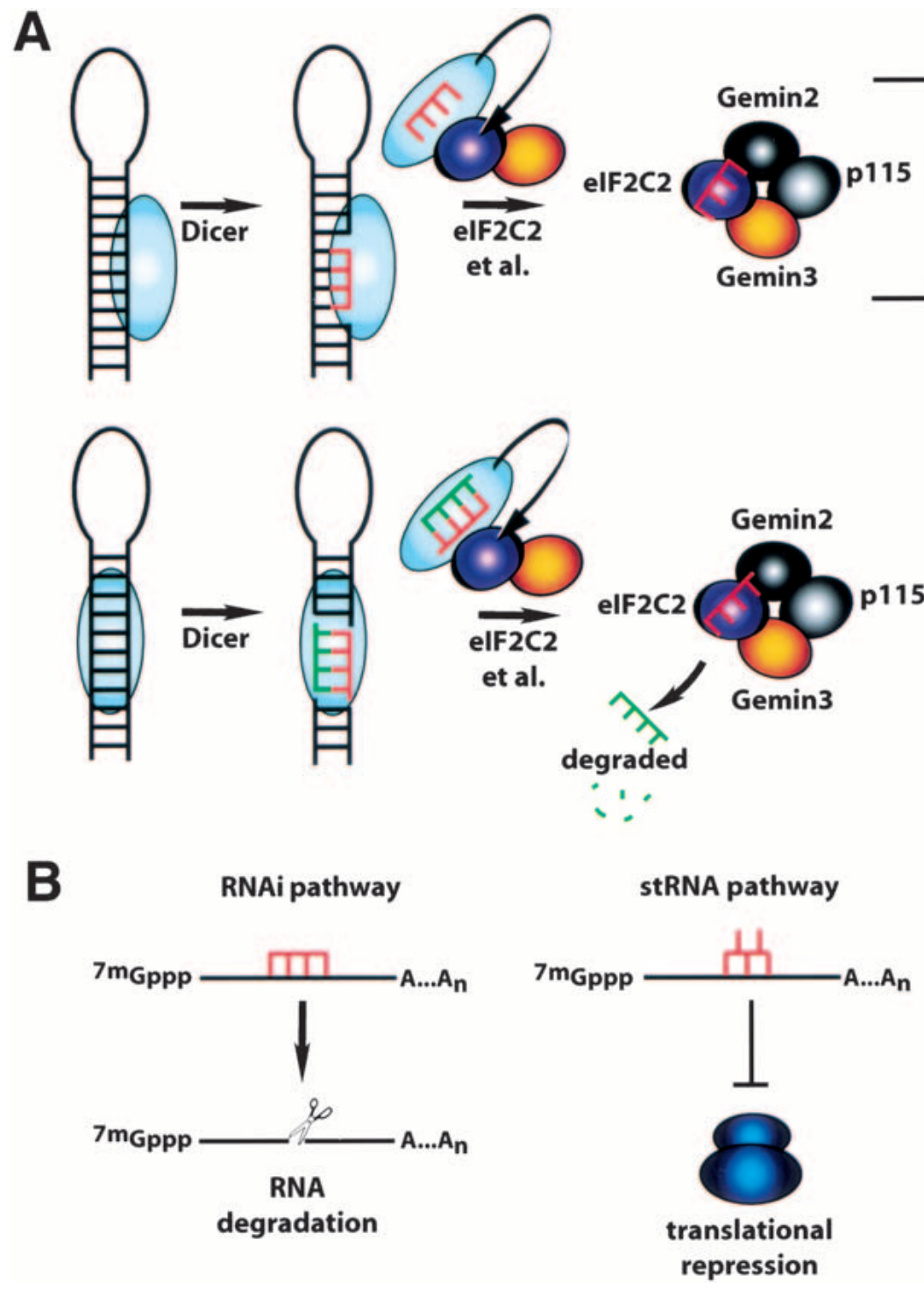

Figure 2. Models for miRNA biogenesis and function. (A) Dicer may cleave a single-stranded miRNA directly from its stem-loop precursor RNA, then transfer the mature miRNA to components of the miRNP. Alternatively, Dicer may initially generate a double-stranded siRNA, then transfer it to the miRNP. Protein components of the miRNP would then unwind the siRNA, select one strand of the siRNA to become the mature, single-stranded miRNA, and catalyze degradation of the other siRNA strand. $(B)$ In the RNAi pathway, a perfectly complementary siRNA targets mRNA for endonucleolytic cleavage. In contrast, miRNAs pair only imperfectly with sequences in the 3' UTRs of their target RNAs and are believed to repress mRNA translation without altering mRNA stability.

DNA, it is surprising that not a single 21-25 nt RNA corresponding to a transposon has been cloned from $C$. elegans or human cells. In contrast, small RNA cloning from trypanosomes, which also contain the RNAi machinery, revealed abundant siRNAs corresponding to retrotransposons (Djikeng et al. 2001). Why have miRNA screens from higher organisms failed to detect such siRNAs? One possibility is that the RNAi pathway plays a major role in silencing transposons only at a highly specific time in development or in a specialized tissue such as germ-cell progenitors. In support of this idea, Tuschl and colleagues reported cloning a small number of siRNAs derived from retrotransposon sequences from syncitial blastoderm stage Drosophila embryos, a stage in development when germ-cell progenitors are formed (Elbashir et al. 2001a).

There are several tantalizing similarities between the miRNP discovered by Dreyfuss and colleagues and the RISC, the RNP that mediates RNAi. First, the sizes of the miRNP $(\sim 550 \mathrm{kD}$; Mourelatos et al. 2002) and the RISC ( 500 kD; Hammond et al. 2000) are quite similar. Second, a helicase-like Gemin3 must play a role in RNAi, because ATP-dependent unwinding of an siRNA duplex is a prerequisite for formation of an active RISC (Nykänen et al. 2001). The putative DEAD-box helicase protein, Spindle E, is required for the RNAi-like silenc- 
ing of the endogenous Stellate locus in Drosophila testes (Aravin et al. 2001; Stapleton et al. 2001), and it will be important to determine whether Spindle E is a component of either a Drosophila miRNP or the RISC, or both. Finally, PPD proteins are found in both the miRNP (human eIF2C2) and the RISC (Drosophila Ago-2). Might the miRNP and the RISC be one and the same, a single RNP with multiple functions? If so, it is tempting to predict that the as-yet-unidentified $115-\mathrm{kD}$ miRNP protein is the elusive Slicer, the ribonuclease postulated to cleave target RNA in the RNAi pathway. Alternatively, the miRNP and the RISC may be distinct complexes containing pathway-specific proteins drawn from the same protein families. In either case, the search for what miRNAs do and how they do it is easier now that we know where they live.

\section{Acknowledgments}

We thank members of the Zamore laboratory for helpful discussions and for comments on the manuscript.

\section{References}

Aravin, A.A., Naumova, N.M., Tulin, A.V., Vagin, V.V., Rozovsky, Y.M., and Gvozdev, V.A. 2001. Double-stranded RNA-mediated silencing of genomic tandem repeats and transposable elements in the $D$. melanogaster germline. Curr. Biol. 11: 1017-1027.

Banerjee, D. and Slack, F. 2002. Control of developmental timing by small temporal RNAs: A paradigm for RNA-mediated regulation of gene expression. BioEssays 24: 119-129.

Bernstein, E., Caudy, A.A., Hammond, S.M., and Hannon, G.J. 2001a. Role for a bidentate ribonuclease in the initiation step of RNA interference. Nature 409: 363-366.

Bernstein, E., Denli, A.M., and Hannon, G.J. 2001b. The rest is silence. RNA 7: 1509-1521.

Billy, E., Brondani, V., Zhang, H., Muller, U., and Filipowicz, W. 2001. Specific interference with gene expression induced by long, double-stranded RNA in mouse embryonal teratocarcinoma cell lines. Proc. Natl. Acad. Sci. 98: 14428-14433.

Bohmert, K., Camus, I., Bellini, C., Bouchez, D., Caboche, M., and Benning, C. 1998. AGO1 defines a novel locus of Arabidopsis controlling leaf development. EMBO J. 17:170180.

Carthew, R.W. 2001. Gene silencing by double-stranded RNA. Curr. Opin. Cell Biol. 13: 244-248.

Catalanotto, C., Azzalin, G., Macino, G., and Cogoni, C. 2000. Transcription: Gene silencing in worms and fungi. Nature 404: 245.

Charroux, B., Pellizzoni, L., Perkinson, R.A., Shevchenko, A., Mann, M., and Dreyfuss, G. 1999. Gemin3: A novel DEAD box protein that interacts with SMN, the spinal muscular atrophy gene product, and is a component of gems. J. Cell Biol. 147: 1181-1194.

Charroux, B., Pellizzoni, L., Perkinson, R.A., Yong, J., Shevchenko, A., Mann, M., and Dreyfuss, G. 2000. Gemin4. A novel component of the SMN complex that is found in both gems and nucleoli. J. Cell. Biol. 148: 1177-1186.

Cikaluk, D.E., Tahbaz, N., Hendricks, L.C., DiMattia, G.E., Hansen, D., Pilgrim, D., and Hobman, T.C. 1999. GERp95, a membrane-associated protein that belongs to a family of proteins involved in stem cell differentiation. Mol. Biol. Cell
10: $3357-3372$.

Cox, D.N., Chao, A., Baker, J., Chang, L., Qiao, D., and Lin, H. 1998. A novel class of evolutionarily conserved genes defined by piwi are essential for stem cell self-renewal. Genes \& Dev. 12: 3715-3727.

Cox, D.N., Chao, A., and Lin, H. 2000. piwi encodes a nucleoplasmic factor whose activity modulates the number and division rate of germline stem cells. Development 127: 503514.

Dernburg, A.F., Zalevsky, J., Colaiácovo, M.P., and Villeneuve, A.M. 2000. Transgene-mediated cosuppression in the C. elegans germ line. Genes \& Dev. 14: 1578-1583.

Djikeng, A., Shi, H., Tschudi, C., and Ullu, E. 2001. RNA interference in Trypanosoma brucei: Cloning of small interfering RNAs provides evidence for retroposon-derived 24-26nucleotide RNAs. RNA 7: 1522-1530.

Elbashir, S.M., Lendeckel, W., and Tuschl, T. 2001a. RNA interference is mediated by 21 - and 22-nucleotide RNAs. Genes \& Dev. 15: 188-200.

Elbashir, S.M., Martinez, J., Patkaniowska, A., Lendeckel, W., and Tuschl, T. 2001b. Functional anatomy of siRNAs for mediating efficient RNAi in Drosophila melanogaster embryo lysate. EMBO J. 20: 6877-6888.

Fagard, M., Boutet, S., Morel, J.-B., Bellini, C., and Vaucheret, H. 2000. AGO1, QDE-2, and RDE-1 are related proteins required for post-transcriptional gene silencing in plants, quelling in fungi, and RNA interference in animals. Proc. Natl. Acad. Sci. 97: 11650-11654.

Grishok, A., Pasquinelli, A.E., Conte, D., Li, N., Parrish, S., Ha, I., Baillie, D.L., Fire, A., Ruvkun, G., and Mello, C.C. 2001. Genes and mechanisms related to RNA interference regulate expression of the small temporal RNAs that control C. elegans developmental timing. Cell 106: 23-34.

Gubitz, A.K., Mourelatos, Z., Abel, L., Rappsilber, J., Mann, M., and Dreyfuss, G. 2002 Gemin5, a novel WD repeat protein component of the SMN complex that binds Sm proteins. $J$. Biol. Chem. 277: 5631-5636.

Hamilton, A.J. and Baulcombe, D.C. 1999. A species of small antisense RNA in posttranscriptional gene silencing in plants. Science 286: 950-952.

Hammond, S.M., Bernstein, E., Beach, D., and Hannon, G.J 2000. An RNA-directed nuclease mediates post-transcriptional gene silencing in Drosophila cells. Nature 404: 293296.

Hammond, S.M., Boettcher, S., Caudy, A.A., Kobayashi, R., and Hannon, G.J. 2001. Argonaute2, a link between genetic and biochemical analyses of RNAi. Science 293: 1146-1150.

Harris, A.N. and Macdonald, P.M. 2001. Aubergine encodes a Drosophila polar granule component required for pole cell formation and related to eIF2C. Development 128: 28232832.

Hutvágner, G., McLachlan, J., Pasquinelli, A.E., Balint, É., Tuschl, T., and Zamore, P.D. 2001. A cellular function for the RNA-interference enzyme Dicer in the maturation of the let-7 small temporal RNA. Science 293: 834-838.

Ketting, R.F. and Plasterk, R.H. 2000. A genetic link between co-suppression and RNA interference in C. elegans. Nature 404: 296-298.

Ketting, R.F., Fischer, S.E., Bernstein, E., Sijen, T., Hannon, G.J., and Plasterk, R.H. 2001. Dicer functions in RNA interference and in synthesis of small RNA involved in developmental timing in C. elegans. Genes \& Dev. 15: 2654-2659.

Knight, S.W. and Bass, B.L. 2001. A role for the RNase III enzyme DCR-1 in RNA interference and germ line development in Caenorhabditis elegans. Science 293: 2269-2271.

Koesters, R., Adams, V., Betts, D., Moos, R., Schmid, M., Sier- 
mann, A., Hassam, S., Weitz, S., Lichter, P., Heitz, P.U., et al. 1999. Human eukaryotic initiation factor EIF2C1 gene: cDNA sequence, genomic organization, localization to chromosomal bands 1p34-p35, and expression. Genomics 61: 210-218.

Kuramochi-Miyagawa, S., Kimura, T., Yomogida, K., Kuroiwa, A., Tadokoro, Y., Fujita, Y., Sato, M., Matsuda, Y., and Nakano, T. 2001. Two mouse piwi-related genes: miwi and mili. Mech. Dev. 108: 121-133.

Lagos-Quintana, M., Rauhut, R., Lendeckel, W., and Tuschl, T. 2001. Identification of novel genes coding for small expressed RNAs. Science 294: 853-858.

Lau, N.C., Lim, L.P., Weinstein, E.G., and Bartel, D.P. 2001. An abundant class of tiny RNAs with probable regulatory roles in Caenorhabditis elegans. Science 294: 858-862.

Lee, R.C. and Ambros, V. 2001. An extensive class of small RNAs in Caenorhabditis elegans. Science 294: 862-864.

Lee, R.C., Feinbaum, R.L., and Ambros, V. 1993. The C. elegans heterochronic gene lin-4 encodes small RNAs with antisense complementarity to lin-14. Cell 75: 843-854.

Meister, G., Hannus, S., Plottner, O., Baars, T., Hartmann, E., Fakan, S., Laggerbauer, B., and Fischer, U. 2001. SMNrp is an essential pre-mRNA splicing factor required for the formation of the mature spliceosome. EMBO J. 20: 2301-2314.

Moss, E.G. 2001. RNA interference: It's a small RNA world. Curr. Biol. 11: R772-R775.

Mourelatos, Z., Abel, L., Yong, J., Kataoka, N., and Dreyfuss, G. 2001. SMN interacts with a novel family of hnRNP and spliceosomal proteins. EMBO J. 20: 5443-5452.

Mourelatos, Z., Dostie, J., Paushkin, S., Sharma, A.K., Charroux, B., Abel, L., Rappsilber, J., Mann, M., and Dreyfuss, G. 2002. miRNPs: A novel class of Ribonucleoproteins containing numerous microRNAs. Genes \& Dev. 16: 720-728.

Nykänen, A., Haley, B., and Zamore, P.D. 2001. ATP requirements and small interfering RNA structure in the RNA interference pathway. Cell 107: 309-321.

Olsen, P.H. and Ambros, V. 1999. The lin-4 regulatory RNA controls developmental timing in Caenorhabditis elegans by blocking LIN-14 protein synthesis after the initiation of translation. Dev. Biol. 216: 671-680.

Pal-Bhadra, M., Bhadra, U., and Birchler, J.A. 2002. RNAi related mechanisms affect both transcriptional and posttranscriptional transgene silencing in Drosophila. Mol. Cell 9: 315327.

Pasquinelli, A.E., Reinhart, B.J., Slack, F., Martindale, M.Q., Kuroda, M.I., Maller, B., Hayward, D.C., Ball, E.E., Degnan, B., Muller, P., et al. 2000. Conservation of the sequence and temporal expression of let-7 heterochronic regulatory RNA. Nature 408: 86-89.

Pellizzoni, L., Baccon, J., Rappsilber, J., Mann, M., and Dreyfuss, G. 2002. Purification of native survival of motor neurons complexes and identification of Gemin6 as a novel component. J. Biol. Chem. 277: 7540-7545.

Reinhart, B.J., Slack, F.J., Basson, M., Pasquinelli, A.E., Bettinger, J.C., Rougvie, A.E., Horvitz, H.R., and Ruvkun, G. 2000. The 21-nucleotide let-7 RNA regulates developmental timing in Caenorhabditis elegans. Nature 403: 901-906.

Reinke, V., Smith, H.E., Nance, J., Wang, J., Van Doren, C., Begley, R., Jones, S.J., Davis, E.B., Scherer, S., Ward, S., et al. 2000. A global profile of germline gene expression in C. elegans. Mol. Cell 6: 605-616.

Ruvkun, G. 2001. Molecular biology. Glimpses of a tiny RNA world. Science 294: 797-799.

Sharma, A.K., Nelson, M.C., Brandt, J.E., Wessman, M., Mahmud, N., Weller, K.P., and Hoffman, R. 2001. Human CD34(+) stem cells express the hiwi gene, a human homo- logue of the Drosophila gene piwi. Blood 97: 426-434.

Sharp, P.A. 2001. RNA interference-2001. Genes \& Dev. 15: $485-490$

Slack, F.J., Basson, M., Liu, Z., Ambros, V., Horvitz, H.R., and Ruvkun, G. 2000. The lin-41 RBCC gene acts in the C. elegans heterochronic pathway between the let-7 regulatory RNA and the LIN-29 transcription factor. Mol. Cell 5: 659669.

Stapleton, W., Das, S., and McKee, B.D. 2001. A role of the Drosophila homeless gene in repression of Stellate in male meiosis. Chromosoma 110: 228-240.

Tabara, H., Sarkissian, M., Kelly, W.G., Fleenor, J., Grishok, A., Timmons, L., Fire, A., and Mello, C.C. 1999. The rde-1 gene, RNA interference, and transposon silencing in C. elegans. Cell 99: 123-132.

Tahbaz, N., Carmichael, J.B., and Hobman, T.C. 2001. GERp95 belongs to a family of signal-transducing proteins and requires Hsp90 activity for stability and Golgi localization. J. Biol. Chem. 276: 43294-43299.

Vaucheret, H., Beclin, C., and Fagard, M. 2001. Post-transcriptional gene silencing in plants. J. Cell Sci. 114: 3083-30891.

Waterhouse, P.M., Wang, M.B., and Lough, T. 2001. Gene silencing as an adaptive defence against viruses. Nature 411: 834-842.

Wilson, J.E., Connell, J.E., and Macdonald, P.M. 1996. aubergine enhances oskar translation in the Drosophila ovary. Development 122: 1631-1639.

Zamore, P., Tuschl, T., Sharp, P., and Bartel, D. 2000. RNAi: Double-stranded RNA directs the ATP-dependent cleavage of mRNA at 21 to 23 nucleotide intervals. Cell 101: 25-33.

Zou, C., Zhang, Z., Wu, S., and Osterman, J.C. 1998. Molecular cloning and characterization of a rabbit eIF2C protein. Gene 211: 187-194. 


\section{Erratum}

Genes \& Development 16: 1025-1031 (2002)

Why do miRNAs live in the miRNP?

Dianne S. Schwarz and Phillip D. Zamore

In Figure 2, panel A, Gemin4 was inadvertently labeled as Gemin2. The corrected figure is printed below along with its legend.

A
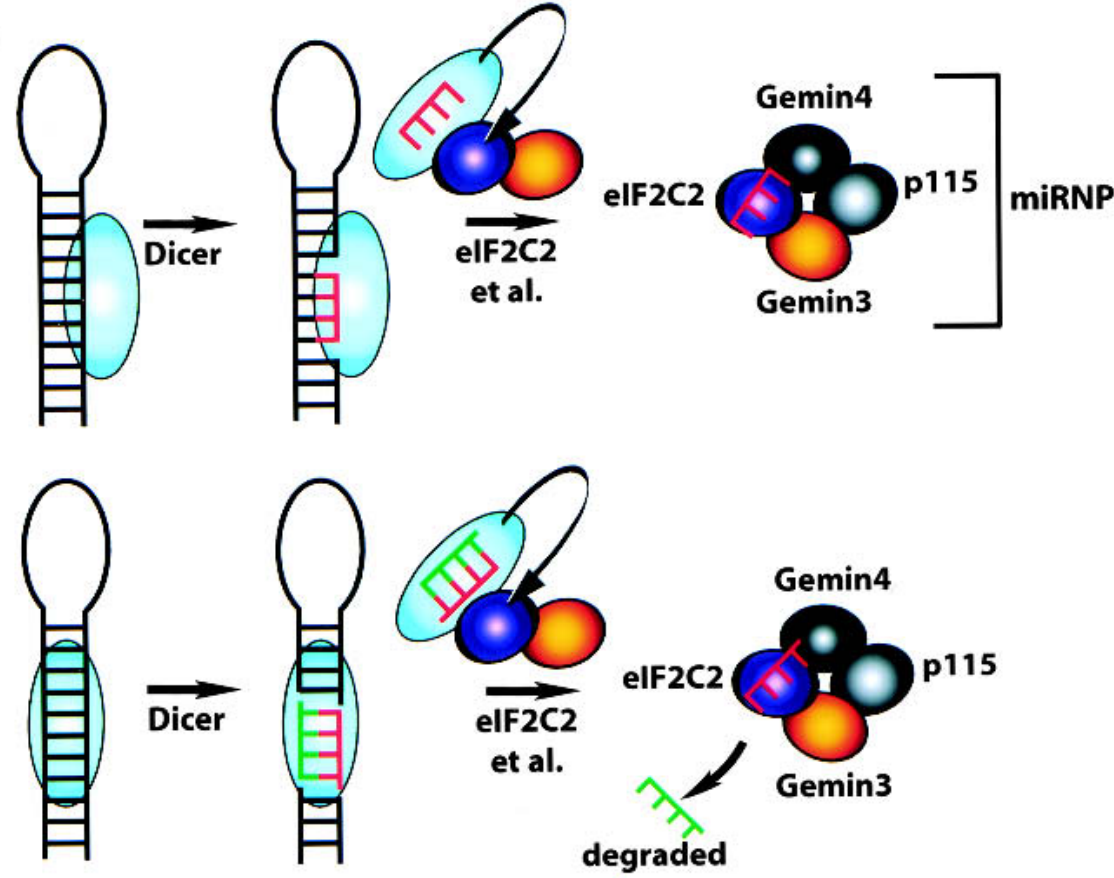

B

RNAi pathway

stRNA pathway
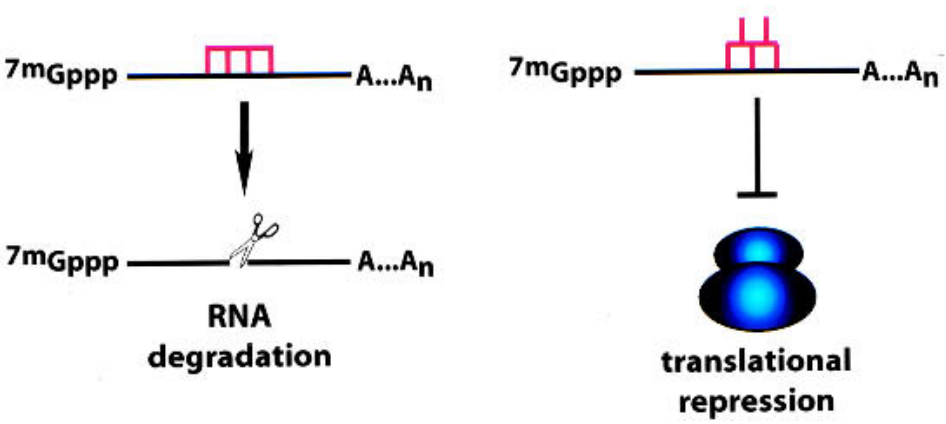

Figure 2. Models for miRNA biogenesis and function. (A) Dicer may cleave a single-stranded miRNA directly from its stem-loop precursor RNA, then transfer the mature miRNA to components of the miRNP. Alternatively, Dicer may initially generate a double-stranded siRNA, then transfer it to the miRNP. Protein components of the miRNP would then unwind the siRNA, select one strand of the siRNA to become the mature, single-stranded miRNA, and catalyze degradation of the other siRNA strand. $(B)$ In the RNAi pathway, a perfectly complementary siRNA targets mRNA for endonucleolytic cleavage. In contrast, miRNAs pair only imperfectly with sequences in the 3' UTRs of their target RNAs and are believed to repress mRNA translation without altering mRNA stability. 


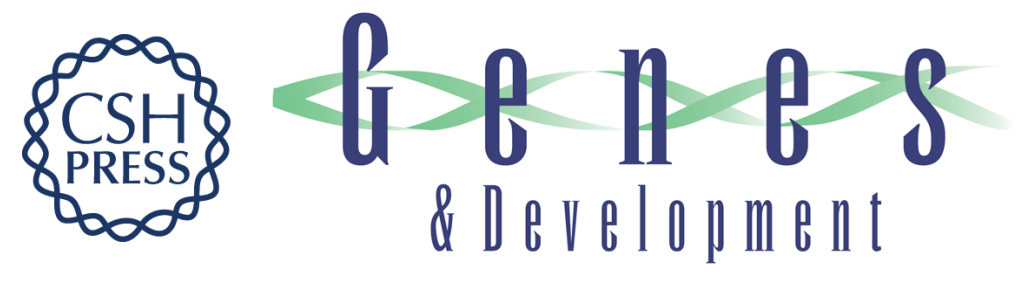

\title{
Why do miRNAs live in the miRNP?
}

\author{
Dianne S. Schwarz and Phillip D. Zamore
}

Genes Dev. 2002, 16:

Access the most recent version at doi:10.1101/gad.992502

Related Content Genes Dev. June, 2002 16: 1582

References This article cites 57 articles, 32 of which can be accessed free at: http://genesdev.cshlp.org/content/16/9/1025.full.html\#ref-list-1

Articles cited in:

http://genesdev.cshlp.org/content/16/9/1025.full.html\#related-urls

\section{License}

Email Alerting Receive free email alerts when new articles cite this article - sign up in the box at the top Service right corner of the article or click here.

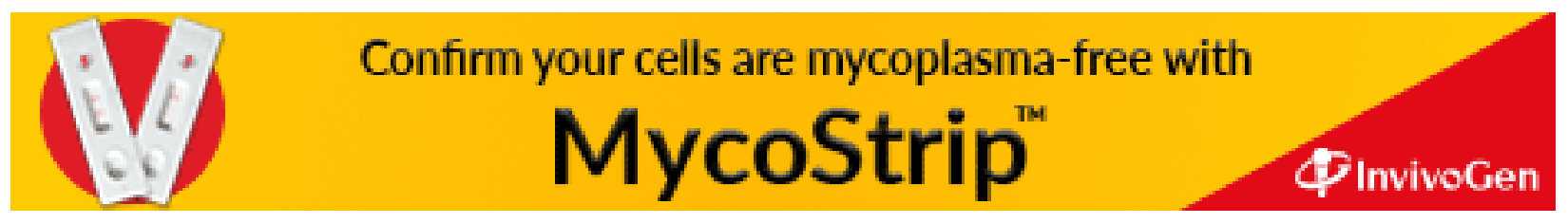

